\title{
Non Linear Causality and Asymmetries in Oil \& Gold: An empirical estimation
}

\author{
Effulgence \\ Vol. 17, No. 2 (Special Issue) \\ July - December 2019 \\ Rukmini Devi Institute of Advanced Studies \\ E-mail : effulgence@rdias.ac.in, Website : www.rdias.ac.in \\ http:/ / effulgence.rdias.ac.in/user/default.aspx \\ https:/ / dx.doi.org/10.33601/effulgence.rdias/v17/iSpl2/2019/31-46
}

\author{
Dr. Rakesh Shahani ${ }^{1} \square$ \\ Rachna $^{2}$
}

\begin{abstract}
The present study empirically investigates the non linear causal and asymmetrical relationship between two strategic commodities oil E gold. The study analyses monthly closing data for the two commodities for the period April 1, 2008-March 31, 2018. The methodology employed under the study includes causality estimation using six proxies for oil viz. oil return, oil return(+), oil return(-), scaled oil return using Standard Deviation, scaled oil return using GARCH E scaled return (+) E scaled return (-). These six proxies would be capturing the non-linear relation between the two variables. Moreover the causality estimation is assumed to be uni-directional from oil to gold either directly or going through the inflation route. To check for asymmetries in impact of oil return on volatility of gold return, both positive and negative oil price changes have been included in the OLS equation. Further asymmetry in volatility of gold returns has also been estimated using T-GARCH Methodology. For testing the stationarity of the variables, DF-GLS test has been employed under the study $\mathcal{E}$ to check for model stability we use CUSUM and CUSUM SQ Plots. The results of the study could not provide a comprehensive evidence of a unidirectional cause effect relation from oil to gold either direct or via inflation route for the period under study. The same was the case with asymmetric impact of oil on gold where the results could not prove the asymmetry in return volatility of gold due to positive and negative oil return. With regards to asymmetry results from T-GARCH, these were significant only at $10 \%$ significance levels. All the variables were however found to be stationary at I(1) using DF-GLS test statistic.
\end{abstract}

Keywords: Causality, Asymmetry, T-GARCH, DF-GLS, Scaled Return

1. Associate Professor, Dept. of Business Economics, Dr. Bhim Rao Ambedkar College (University of Delhi), rakesh.shahani@bramb.du.ac.in, rakesh.shahani@gmail.com (also the corresponding author)

2. Student, BA (H) Business Economics, Dr.Bhim Rao Ambedkar College (University of Delhi), rachnaprakash746@gmail.com 


\section{INTRODUCTION}

$\mathrm{O}$ il and Gold are the two strategic commodities that have gained interest amongst the researchers especially after the surge in their prices and associated heightened volatility. If we compare the two commodities in terms of their significance, we find that whereas crude is the world's biggest traded commodity, gold is popular amongst investors as it has unique diversification qualities. Gold is commonly called a "safe haven" \& a tool of risk management used in hedging inflation risk. A study by Jaffe (1989)showed that even with an investment in Gold which can be as low as 5\% with rest $95 \%$ in other assets, there is a substantial risk reduction \& return augmentation of the portfolio.

The empirical studies have shown that the importance of gold as an asset can be known only when there is a financial crisis; this is so because during a crisis when equities fall, almost all other assets follow; gold on the other hand however maintains its value (Chua 1990). On the other hand, gold as a hedge may not work well for every financial market, this may be an excellent hedge for equities in major equity markets including US but not for equity markets in emerging economies. Moreover Gold cannot be considered as a hedge against other commodities (Baur \& Mc. Dermott 2010) Talking of crude; researchers have shown that a rise in Crude prices does impact the equity markets adversely but such an impact is with a lag. Also for Oil, not only rise in prices but also rise in volatility is also associated with reduced returns on equities. Many researchers also feel that impact of crude on equities is highly asymmetrical as here supply shocks are more important than demand shocks. In terms of hedging, it has been noticed that since a negative relation exists between oil \& equities, the oil does provide a long term hedge (Ciner, C.et.al 2013).

When we talk of gold and oil together, the earliest connection between the two commodities could be traced as early as 1933 when the Middle East wanted gold in exchange for crude oil(Simakova J. 2011).
Most researchers in this area are of the view that a host of common macro-economic variables influence the movement of these two commodity prices and these include interest \& exchange rates, inflation, GDP growth etc. (Hammoudeh et.al 2008, Le, T. H., \& Chang, Y. 2011A ) Then economists and policy makers have identified four routes whereby one can link movement of oil to gold. The first route and the most popular route is through inflation i.e. rise in oil prices often leads to rise in overall inflation which also moves the price of gold, thus during the times of rising prices, one could use the yellow metal as an inflation hedge, (see Reboredo 2013; Jaffe 1989; Hooker 2002; Hunt 2006).

The second route of linking gold with oil is via economic growth. According to some authors, rise in oil prices adversely impacts economic growth \& stock prices (although this is with a lag), therefore in times of falling stock prices, growth and rising crude investors have the tendency to shift to gold which is regarded as a safe haven against oil price rise leading to a rise in the prices of Gold(see Baur \& McDermott 2010).The third route has been more region specific and looks at from the angle of oilexporting countries. i.e. a rise in oil prices adds to the incomes of oil exporters which is invested mainly in gold \& thereby raising its demand \& also its price. (see Melvin \& Sultan 1990). The fourth route is the outcome of depreciation of US Dollar. When US dollar depreciates, oil prices start rising \& investors pile up gold more than any other asset, thereby pushing up its price (see Joy2011).

Thus from the above discussion it is clear that different theories which have come up linking gold with oil clearly support that movement of gold and oil should follow cause-effect relation either direct or indirectly through another variable movement, however the surprizing fact is that empirical studies done by a large no. of researchers have proved it otherwise. Therefore keeping in view these considerations, an attempt has been made to study the causal relation between the movement of two commodities; oil and gold. The study has explored 
unilateral causality both as a direct impact \& indirect impact (through inflation channel) of return on oil on gold. Further to make a comprehensive study out of this relation, the study has also experimented with six different proxies of oil (return on oil, positive \& negative return on oil, scaled return \& scaled positive and negative return on oil) which could have a likely impact on return of gold. The period of study is ten years (April 1, 2008- March 31, 2018) \& the analysis under the study has been carried out using monthly closing data at first difference (in terms of return) for the two commodities viz. oil and gold. The data sources include websites of investing.com \& nseindia.com

\section{REVIEW OF LITERATURE}

The review of literature includes a mix of studies which have tested the relation between Oil and Gold and also these two variables against other financial assets. Besides we have included few studies pertaining to futures market while majority of these relate to the spot market. Most of the studies which have tested the relation under spot market have analysed their relation under non -linear relation and using non-linear time series tools like non-linear causality and Non Linear ARDL. It is important to note that very few studies have found a linear relation between the two. Some studies have also tested their relation by including more variables thereby testing for their hedging and/or safe haven parameters.

Raza, N et.al. (2016) tested using non linear ARDL methodology the impact of oil and gold in the short \& long run on stock markets of emerging economies for the period Jan-08-June 15. The study also explored the asymmetries of the stock market returns due to these two commodities. The results showed that gold had a positive impact on returns of most of the larger emerging economies while oil had a negative impact on the returns of almost all emerging economies. As far as the volatilities were concerned, both oil \& gold had a negative impact on stock market returns both in short \& long run with higher vulnerability towards unfavourable events Bampinas, G., \& Panagiotidis, T. (2015) examined causal relationship between oil \& gold with linear \& non-linear Granger causality tests. The results showed that the two commodities were more interlinked especially after the 2008 crisis. However the causality detected (both linear and non-linear) disappeared after filtering was applied. Further during the crisis period, oil consistently influenced gold in various sub- samples but gold did not influence oil, thereby showing that gold was ideal for volatile markets.

Ciner, C et.al.(2013) examined why gold and oil were called hedgers \& how well did these performed against the equities, bonds or dollar. They also examined how these two commodities vary with time. The findings showed that gold was an excellent hedge against all the financial assets as its return was negative against these assets. Further according to them, oil must not be considered as a long term hedger asset. this is mainly because oil prices were determined by specific demand \& supply shocks which were entirely different from shocks in the gold market Reboredo, J. C. (2013) explored gold as a hedge \&/or safe haven viz. a. viz. oil \& by taking weekly data for the period Jan 2000Sep 2011. The results showed that gold could not be used as a hedge against oil as there was some correlation \& dependence between their movement. However in case of extreme price movements in oil, gold could serve as safe haven as the two markets were found to be moving independently in extreme situations. This was tested in their approach which was based on copulas to analyse the dependence structure between these two markets. Hussin, M. Y. M et.al (2013) studied the relationship between prices of two commodities oil \& gold \& its impact on Malaysian Shariah Index for the period Jan 2007- Dec 2011. The econometric tools applied were Cointegration, Causality VAR with Impulse \& Variance Decomposition. The results showed that stock returns were not co-integrated with these commodities, however bilateral causality was observed between stock return and oil price returns 
No causality was however noticed between gold \& stock returns indicating that gold could not predict Malaysian Shariah Index

Le, T. H., \& Chang, Y. (2011) made a study of gold and oil together with other financial variables like stock prices, interest rate \& exchange rate for Japan by employing ARDL bounds test. The results showed that in the long run, stock and gold prices had positive impact on the interest rate showing that the rise in the stock and gold prices could spiral inflation \& eventually interest rate. Further since higher inflation could mean depreciation of yen \& loss to investors holding yen in their portfolio which according to them could be overcome by including stock or gold in their portfolio. ECM results showed movements in gold could predict interest rates fluctuations in Japan, however the equilibrium correction was found to be quite slow. Le, T. H., \& Chang, Y. (2011 A) empirically investigated the price relation between oil \& gold by using different oil price proxies with the objective of testing the asymmetric \& also non-linear impact of oil on gold \& inflation. The results did prove the long run cointegrating relation between oil \& inflation, oil \& gold and also between gold \& inflation. The Causality supported the oil -gold relationship through inflation channel. However different proxies used for oil could not prove that oil prices have an asymmetric effect on gold or even on inflation. The non linearity was however proved with respect to inflation.
Zhang, Y. J., \& Wei, Y. M. (2010) tested for the interaction between gold \& crude oil with respect to co-integration, causality \& price discovery. The study found that magnitude of volatility of crude was higher than that of gold, although there is an overall increase in volatility of both the commodities. The correlation between the two was very high at +0.9295 with long term co-integration also being proved under the study. The influence of one variable on another showed that gold's influence was five times than oil's influence on gold. However the contribution of crude oil on global development was seen to be far more than gold. Linear Granger Causality from oil to gold was observed but not vice versa mainly due to surging oil prices. Non Linear Granger Causality was however not observed. Malliaris, A. G., \& Malliaris, M. (2009) analyzed the price inter-relation amongst three variables; gold, oil $\&$ the Euro using time series and neural network methodology. The time series revealed both shortterm \&long-term relation amongst all the three variables, with oil adjusting to gold. Further it was found that euro \& oil had almost same impact on each other. On the other hand the relation between gold \& euro was found to be rather weak. The neural network indicated that impact of oil was more on gold than vice versa, similarly oil's impact on euro was higher than euro on oil \& finally gold's impact on euro was fast \& also higher than euro's impact on gold.

\section{STATISTICAL DESCRIPTION OF DATA \& DIAGNOSTIC TESTS}

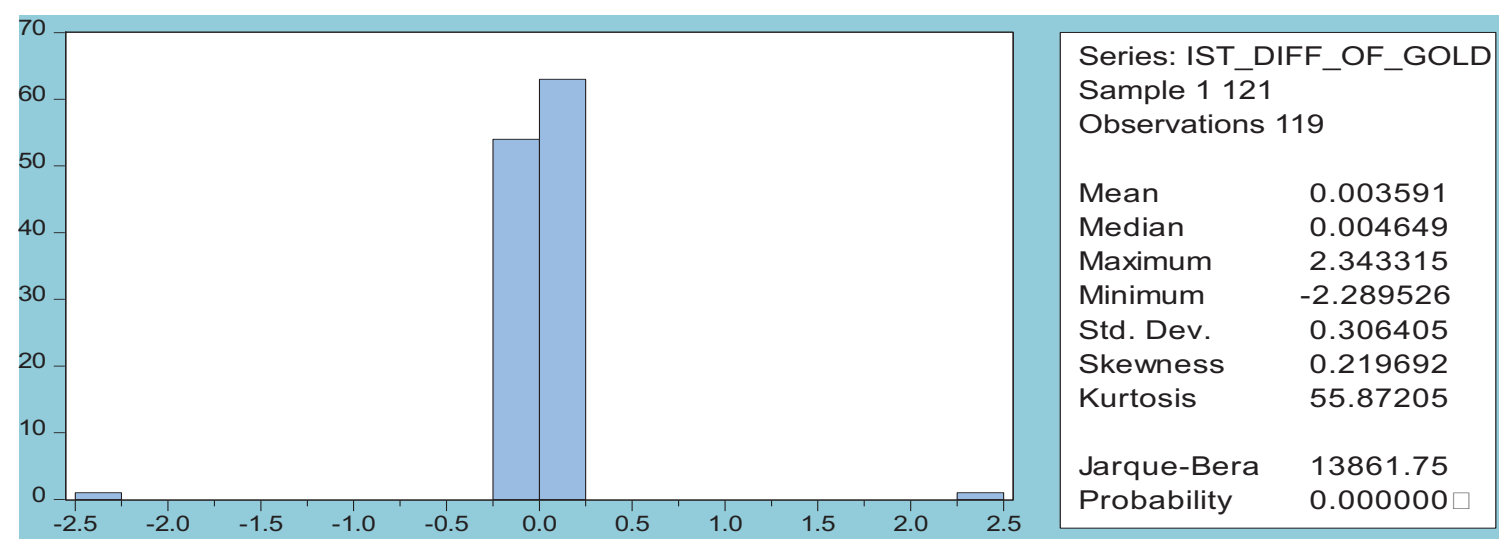

Fig (i) Statistical Description of Return on Gold Prices 


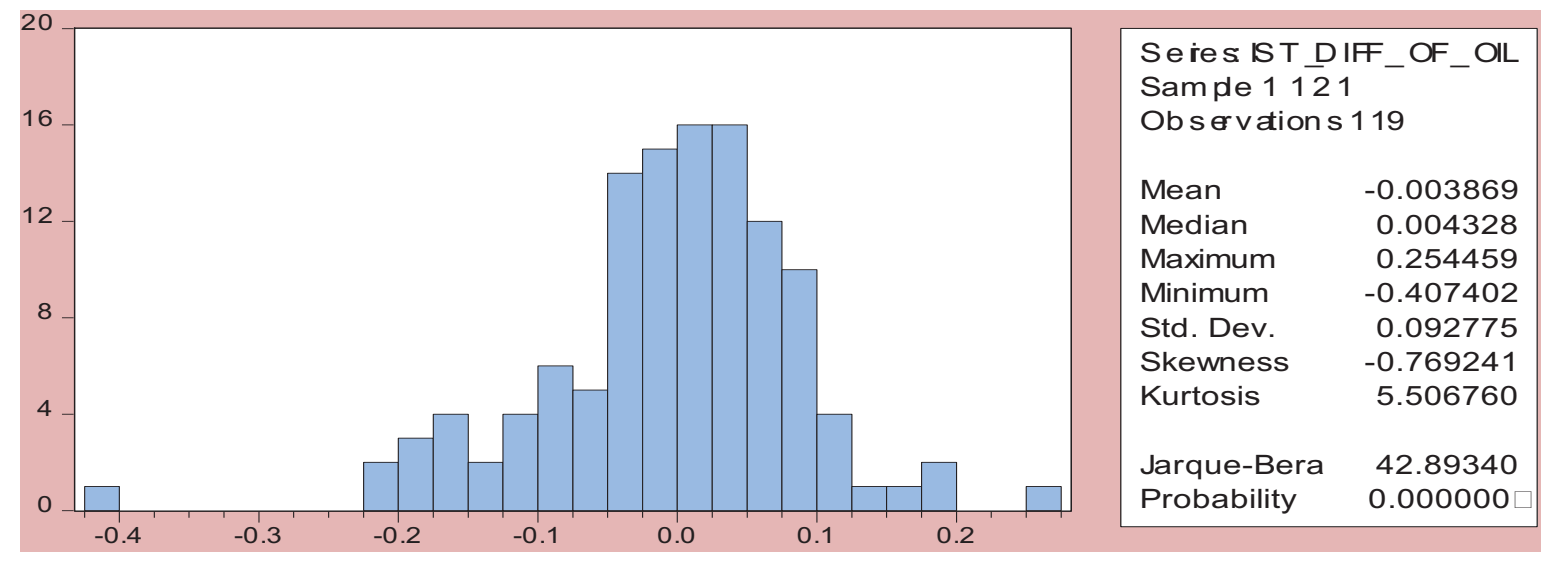

Fig (ii) Statistical Description of Return on Oil Prices

A Comparative Analysis pertaining to the Statistical Description of oil and gold return for the period April 2008March 2018; Fig (i) \& (ii) is given as under :-

\begin{tabular}{|l|l|l|}
\hline Statistic & Return on Oil & Return on Gold \\
\hline Mean Monthly Return & Negative & Positive \\
\hline $\begin{array}{l}\text { Standard Deviation } \\
\text { (reflecting volatility of returns) }\end{array}$ & Low & Quite High \\
\hline Skewness of the Distribution & Negatively Skewed & Positively Skewed \\
\hline Kurtosis of the Distribution & $\begin{array}{l}\text { Slightly Fatter Tail than } \\
\text { Normal }\end{array}$ & Leptokurtic \\
\hline Max\& Min Monthly Return & $+0.25,-0.41$ & $+2.34,-2.38$ \\
\hline Compared to Normal Dist. & Not Normal & Not Normal \\
\hline
\end{tabular}

Stationary Diagnostics of Gold and Oil

To test for stationarity of our variables, we have applied Dickey Fuller Generalized Least Squares (DF GLS) developed by Elliott, Rothenberg and Stock (ERS) which is proved to have higher power and works correctly even with small samples than ADF Unit Root test.

The following two equation have been constructed to test stationarity of our variables

$$
\begin{aligned}
& \Delta \ddot{o i} l_{t}=\alpha_{1} \ddot{O i} l_{t-1}+\sum_{i=1}^{m} \alpha_{i} \Delta \ddot{O i} l_{t-i}+u_{t} \\
& \Delta G \ddot{o l d}{ }_{t}=\beta_{1} G \ddot{o l d} t_{t-1}+\sum_{j=1}^{m} \beta_{i} \Delta \text { Göld }{ }_{t-j}+v_{t}
\end{aligned}
$$

( where $\ddot{O l l}_{t} \&$ Göld are the two de-trended variables, $\pm_{1}$ and ${ }^{2}{ }_{1}$ are the two coefficients which test for the stationary of our variables. "Öll $t_{t-i}$ and "Göld $t_{t-j}$ are the augmentation terms which take care of serial correlation in time series and these are added ' $m$ ' times till serial correlation is removed. Note since we are working on de-trended data it would exclude intercept and time variable)

\section{Stability \& Non Linearity Diagnosis}

To identify the non linearity of our variables we would be using the popular Cumulative Sum of Residuals (CUSUM) \& Cumulative sum of squared recursive residuals (CUSUM SQ) tests. 
(i) CUSUM :

$$
C_{r}=\sum_{r=1}^{n-1} w_{r}, W_{r}=\left(\frac{r^{e s_{r t}}-\overline{r e s_{r}}}{\sigma_{r e s_{r t}}}\right),
$$

Where $W_{r}$ are the normalized residuals and follows the following formula $r$ being the regression number.

(ii) CUSUM SQ :

$$
C S Q_{r}=\sum_{r=2}^{n} w_{r}^{2}
$$

ARCH Diagnosis

To determine whether $\mathrm{ARCH}$ Model is required we would be using the Heteroscedasticity $\mathrm{ARCH}$ test where the. Null Hypothesis (Ho) being No Heteroscedasticity.

\section{RESEARCH METHODOLOGY}

Under research methodology first we would be developing different proxies of oil which we shall be using in our research. Then we would develop the equations for testing the causality amongst the variables followed by the asymmetry tests

\section{(i) Developing Six Proxies of Variable Oil:}

Since we have to establish the relation between Oil and Gold in both linear and non linear terms we have used six different proxies for oil.

(a) The first proxy is the usual return of oil :

Return on Oil Price $_{t}=$ Oil Price $_{t}-$ Oil Price $_{t-1}$

(b) The second proxy for oil takes only positive values from Return on Oil Price, i.e. we consider only those months when there has been a rise in the price of oil and for those months where there is a fall in price of oil, we take the value as ' 0 ' i.e.

Return on Oil Price $_{t}{ }^{(+)}=\max (0$, Return on Oil Price $)$

(c) The third proxy takes the opposite view i.e. considers only negative values from Ret. in Oil Pricet $\&$ for months where there has been a rise, the variable takes the value ' 0 '

Return in Oil Price ${ }_{t}{ }^{-}=\min (0$, Return on Oil Price $_{\mathrm{t}}$ ) (d) The fourth proxy is the scaled return for Oil where we divide Return in Oil Price with Standard Deviation of the Oil returns.

Thus Scaled return on oil $=$ Return on Oil Price $_{t} / \sigma_{t}$.

Another variant of this proxy is where we consider oil returns volatility as obtained by the GARCH(1,1) Model. The GARCH(1,1) model which has both mean and variance equations takes the following form :

Mean Equation: Ret on Oil ${ }_{t}=\beta_{1}+\beta_{2}$ Ret Oil Price $_{t-1}+u t$

$\mathbf{u}_{\mathrm{t}} \sim \operatorname{iid} \mathbf{N}\left(0, \sigma^{2} \mathbf{u}_{\mathrm{t}}\right)$

Variance Equation : $h_{t}($ Ret on Oil $)=a 1+a 2 u_{t}^{2}$. $+\chi h_{t-1}$

(e) The fifth and sixth proxies are scaled return positive and scaled return negative i.e.

Scaled Return Positive $=\operatorname{Max}[0$, Scaled Return on Oil $\left.{ }_{t}{ }^{(+)}\right]$\&

Scaled Return Negative $=$ Min $[0, \quad$ Scaled Return on Oil ${ }_{t}^{(-)}$]

Here too the usual Standard Deviation and GARCH versions have been used for scaled returns.

(ii) Test for Causality Relation amongst the variables

Under test of causality amongst the variables, we make an assumption that causality flows from Oil to Gold Directionally i.e. we would be interested in test of causality hypothesis : flowing only in one direction. Further the study has considered both direct flow (Oil $\rightarrow$ Gold) and indirect flow using inflation channel(Oil $\rightarrow$ 
Inflation $\rightarrow$ Gold). Thus under indirect flow, a rise in the oil prices causes inflation which further leads to rise in price of gold. This has been tested first by developing a cause - effect relation between oil \& inflation, then again between inflation and gold. Now if the above channel is proved to be true, we should get the same positive result as obtained by developing a causality directly between gold and oil.

\section{(a) Channel A: Oil $\rightarrow$ Inflation}

We shall be using all our six proxies of oil stated above and therefore the following models have been developed :-

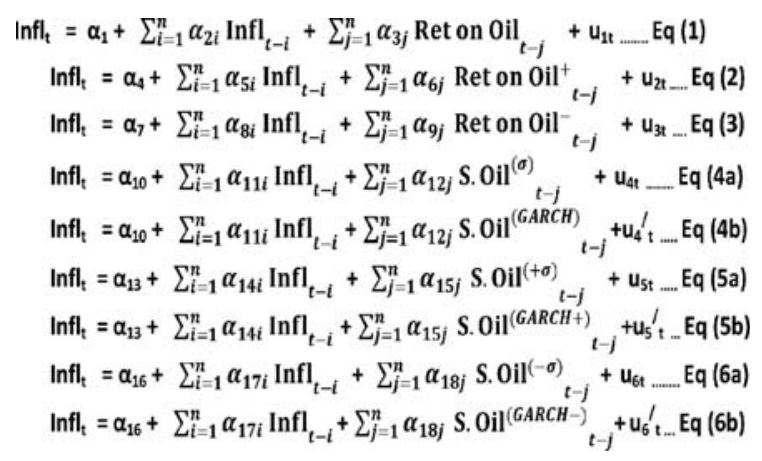

(b) Channel B: Inflation $\rightarrow$ Gold

For Inflation impacting Gold, there shall be only one equation which is given as under :-

Ret on Gold ${ }_{t}={ }_{1}+\sum_{j=1}^{m} \beta_{2 j}$ Ret on Gold ${ }_{t-j}+\sum_{j=1}^{m} \beta_{3 i} I n f_{t-j}{ }+e_{1} \ldots$ Eq (6c)

(c) Channel C: Oil $\rightarrow$ Gold

Here too we shall be developing the six models using all our six proxies of oil

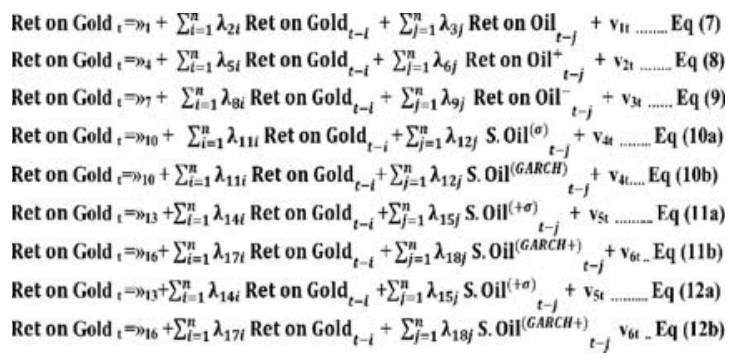

(iii) Test for Asymmetries in relation between oil and gold

The relation between oil and gold has also been tested for asymmetry i.e. whether or not the impact on return of gold due to oil price increase and decrease is same. It would also test whether there is asymmetry in volatility of returns of gold due to oil price rise and fall. To test for this asymmetric relation we have employed two methodologies ; first we would be using the above computed proxies (positive and negative return of oil or scaled positive and negative return) and using these together in our regression model \& testing for their significance and interpreting their beta values to ascertain asymmetry in returns i.e. for every percent change in oil, what is the percent change in gold when we take positive return of oil and negative return of oil. The second methodology employs popular T-GARCH technique to detect for any asymmetry where our objective is to detect asymmetry in return volatility of oil. Here we introduce a term called 'DT' i.e. threshold dummy in the variance equation which when added to error term which takes the value as ' 1 ' for a negative impact of oil on gold while it shall be ' 0 ' otherwise. Thus by doing so, for every bad news there would be an impact of ' $\left(a_{2}+p\right)$ ', while every good news there would be an impact of only ' $\mathrm{a}_{2}$.

All the equations developed for testing asymmetry are given as under :-

(i) Using positive return of oil and negative return of oil Ret on Gold $=\lambda_{1}+\sum_{i=1}^{n} \lambda_{2 i}$ Ret on Gold $t-i+\sum_{j=1}^{n} \lambda_{3 j}$ Ret on Oil $_{t-1}$

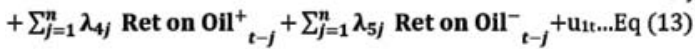

(ii) Using scaled positive return of oil and scaled negative return of oll

Ret on Gold $=\theta_{1}+\sum_{i=1}^{n} \theta_{2 i}$ Ret on Gold $t_{t-i}+\sum_{j=1}^{n} \theta_{3 j}$ S. Oil $_{t-j}+$ $\sum_{j=1}^{n} \theta_{4 j}$ S. Oil $(+)_{t-j}+\sum_{j=1}^{n} \theta_{5 j}$ S. Oil $(-)_{t-j}+u_{2 t} \ldots . . . . E q(14)$

(iii) Using T-GARCH technique

Mean Equation : Ret. on Gold $\mathrm{t}=\lambda_{1}+\sum_{t=1}^{n} \lambda_{2 i}$ Ret on Gold $_{t-t}+$ $\sum_{j=1}^{n} \lambda_{3 j}$ Ret on Oil ${ }_{t-j}+\mathrm{u}_{\mathrm{t}}$.......Eq (15)

$u_{t} \sim$ iid. $N\left(0, \sigma^{2} u_{t}\right)$

VarianceEquation $h_{f}=\alpha_{1}+\sum_{j=1}^{p}\left(\alpha_{2 j}+\pi_{j} D T_{t-j}\right) u_{t-j}^{2}+\sum_{i=1}^{q} \alpha_{3 i} h_{t-t}$ 


\section{RESULTS \& INFERENCES OF THE STUDY}

The results of the study are given in appendices in a tabular format. Appendix I gives the results of tests for Stationairty of variables using DF-GLS test (trend and intercept). The table shows the computed ' $t$ ' values of two variables; Gold and Oil both at levels and 1st difference, however both the variables have their absolute computed values higher than the table value ( Elliott-Rothenberg DF-GLS Test critical value at $5 \%$ ) only at 1 st difference thus making these stationary only at 1 st difference.

Appendix II \& III gives the results of tests of Causality between the two variables; Gold and Oil . Whereas Appendix II gives the Causality test from Oil to Gold via Inflation route, Appendix III gives the causality results direct from Oil to Gold. In Appendix II we have two tables, Table II-A giving results of Causality test from Oil to Inflation and Table II-B from Inflation to Gold. For Causality from Oil to Inflation (Table II-A we have obtained results of all nine equations representing six different proxies of oil (eq. 1 to eq. 6(b)) .None of these nine equations show any causality moving from oil to inflation. Coming to Table II-B which gives the results of causality flowing from Inflation to Gold,(eq. 6(c)) we find that causality does flow from Inflation to Gold i.e. Unilateral Causality exists. The next causality results; from Oil to Gold (Direct) are given in Appendix III. These results also show no direct flow of causality from Oil to Gold. Here too all the nine equations have been constructed (eq. 7 to eq. 12(b)) but as with the indirect channel, here too none of the nine equations show any causality flowing from Oil to Gold. Therefore the inference drawn from the causality results is that no causality flows from Oil to Gold either directly of through inflation route for the period of study April 2008March 18 when we take the monthly closing prices of these variables.

Appendix IV gives the results of impact of asymmetric impact of oil on gold return. The results obtained under this test would enable us to know whether or not the impact on return of gold due to oil price increase and oil price decrease is same. To test for this asymmetric relation we had employed two methodologies ; results of the first methodology can again be divided into two, one which uses positive and negative return of oil [Table IV (a)] and second which uses scaled positive and negative return of oil [Table IV (b))]. The second methodology used to test asymmetry was T-GARCH whose results are given in [Table IV (c)]. A glance at the results from Table IV (a) \& (b) clearly indicate there is no asymmetry in returns of gold for rise or fall in oil prices as the coefficient of positive (or scaled positive ) \& negative (or scaled negative) proxies of oil were found to be insignificant. On the other hand asymmetry test results of T-GARCH given in Table IV (c) shows that the coefficient of T-GARCH term showing asymmetry i.e. $\left(\operatorname{RESID}(-1)^{\wedge} 2^{*}(\operatorname{RESID}(-\right.$ 1)<0)) was significant but only at $10 \%$ levels. Thus the inference drawn from the test of asymmetry clearly shows no asymmetry in returns of gold due to rise \& fall in price of oil, further asymmetry in return volatility was found only at $10 \%$ level of significance.

Appendix $\mathrm{V}$ gives the results of our selection of no. of lags for each of our causality models. The Lag selection criteria techniques employed include Forecast Prediction Error (FPE), Akaike Information (AIC), Schwarz Criteria(SC) \& Hannan-Quinn (HQ) \& Likelihood Ratio (LR). To get a clear selection of the optimal model, maximum no. of lags were placed at 15 . The results showing optimal lags for (i) Oil $\rightarrow$ Inflation, (ii) Inflation $\rightarrow$ Gold \& (iii) Oil $\rightarrow$ Gold Causality are presented in Table (V-A), (V-B) \& $(\mathrm{V}-\mathrm{C})$ respectively. In all the three tables, the different criteria used do not give a consensus about the of no. of lags therefore we decided to stick to the no. of lags which have been identified as common by two or more techniques. Thus in case of Causality flowing from Oil $\rightarrow$ Inflation, we take lag ' 1 ' as it is recommended by two techniques \& including the more popular \& widely accepted AIC criteria. In case of Causality flowing from Inflation $\rightarrow$ Gold we have identified lag ' 3 ' as most optimal as it is 
recommended by three of possible five criteria (including AIC) and finally for Causality flowing from Oil $\rightarrow$ Gold, the lag decided is ' 2 ' here too three criteria (including AIC) are recommending this lag as optimal.

Appendix VI gives the results of $\mathrm{ARCH}$ Heteroscedasticity test. Here the Null Hypothesis of No Heteroscedasticity is clearly rejected as both Observed R square and F Statistics have their ' $\mathrm{p}$ ' values lower than the critical 0.05 , showing the existence of heteroscedasticity and therefore the Model must incorporate the ARCH effect.

Appendix VII gives the two figures; CUSUM \& CUSUM SQ which are used for model stability and the model (or parameters) are stable if they lie within the $5 \%$ level. In our case both the curves; CUSUM \& CUSUM SQ are seen crossing the limits of $5 \%$ and therefore the model is not stable, hence non linearity is proved which may be either due to a structural break in time series or model being of a different functional form.

\section{CONCLUSION \\ AND RECOMMENDATIONS \\ POLICY}

The present study investigated the non linear causality \& asymmetry in relationship between two strategic commodities oil \& gold by taking monthly closing data for the period April 1, 2008- March 31, 2018. The methodology employed was causality estimation using six proxies for oil viz. oil return, oil return(+), oil return(-), scaled oil return using Standard Deviation, scaled oil return using GARCH \& scaled return (+) \& scaled return (-) from oil to gold directly and through the inflation route. The asymmetry in returns was checked by including both positive and negative oil price changes in the OLS regression. Further asymmetry in volatility of gold returns was also estimated using T-GARCH Methodology. For testing the stationarity of the variables, DF-GLS test was employed \& for model stability CUSUM and CUSUM SQ Plots. The results of the study could not provide a comprehensive evidence of a uni-directional cause effect relation from oil to gold either direct or via inflation route for the period under study. The same was the case with asymmetric impact of oil on gold where the results could not prove the asymmetry in return of gold due to positive and negative oil return. With regards to asymmetry in volatility of returns while employing T-GARCH Model, the relevant coefficient reflecting asymmetry was found to be significant but only at 10 $\%$ significance levels.

The results obtained from the study throws some useful information for the portfolio investors/managers \& also policy makers; firstly no uni-directional cause-effect relation from oil to gold proved in the study would simply mean that lagged information of Oil markets cannot influence \& be used as a forecasting tool in the gold market, secondly no uni-directional causality could also be used by the investors during the time when the price of oil is falling continuously . Here the investors can easily switch to gold as such oil price fall would not cause any impact on the price of gold. Thirdly the statistical analysis of the returns of both variables has revealed that investors in gold got positive mean monthly return during the ten year period (2008-18) which was $200 \%$ more than the return from oil during the same period. Also during this period, the return from oil was negative while that from gold was positive. This clearly gives a signal to the investor that if given a choice, to include just one asset out of the two in their portfolio, the straight forward choice would be gold. However analysis also shows that this additional return of gold also comes at an additional risk which is higher by $70 \%$ approximately than the risk in case of oil. Now although risk in case of oil is considerably lower than gold, a rational investor should keep away from investing in oil as it is giving negative returns during the study period and a better and much safer option here would be investment in Government Securities which would give a nominal return but at almost zero risk. Fourthly the results also showed that asymmetric returns do not exist in gold markets. This information is precious especially to those 
portfolio investors who stop investing in gold markets as and when any bad news strikes the market. Their action is the outcome of asymmetric returns which exist in other financial markets especially stock markets (impact of bad news is far more than good news on financial markets). Now with no asymmetrical impact being proved in our study, such investors need not unnecessarily worry about the impact of such a news on gold markets.

\section{REFERENCES}

1) Bampinas, G., \& Panagiotidis, T. (2015) On the relationship between oil and gold before and after financial crisis: linear, nonlinear and timevarying causality testing. Studies in Nonlinear Dynamics \& Econometrics, 19(5), pp.657-668.

2) Baur, D. G., \& McDermott, T. K. (2010) Is gold a safe haven? International evidence. Journal of Banking \& Finance, 34(8), pp.1886-1898.

3) Chua, J., G. Stick, \& R. Woodward ( 1990) Diversifying with Gold Stocks, Financial Analysts Journal 46, pp.76-79.

4) Ciner, C., Gurdgiev, C., \& Lucey, B. M. (2013) Hedges and safe havens: An examination of stocks, bonds, gold, oil and exchange rates. International Review of Financial Analysis, 29, pp.202-211.

5) Hammoudeh, S. Sari R. \& B.T. Ewing (2008) Relationships among strategic commodities and with financial variables: A new look. Contemporary Economic Policy, Vol 27(2), pp. 251-264.

6) Hooker, M. A. (1999) Are Oil Shocks Inflationary. Asymmetric and Nonlin) ear Specifications Versus Changes in Regimes; Board of Governors of the Federal Reserve System :WP.

7) Hunt, B. (2006) Oil price shocks and the US stagflation of the 1970s: Some insights from GEM. The Energy Journal, pp.61-80.

8) Hussin, M. Y. M., Muhammad, F., Razak, A. A., Tha, G. P., \& Marwan, N. (2013) The link between gold price, oil price and Islamic stock market: Experience from Malaysia. Journal of Studies in Social Sciences, pp.4(2).
9) Jaffe, J. F. (1989) Gold and gold stocks as investments for institutional portfolios. Financial Analysts Journal, pp. 53-59.

10) Joy, M. (2011) Gold and the US dollar: Hedge or haven?. Finance Research Letters, 8(3), pp.120131.

11) Le, T. H., \& Chang, Y. (2011) Dynamic relationships between the price of oil, gold and financial variables in Japan: a bounds testing approach. (available at www.mpra.ub.unimuenchen.de)

12) Le, T. H., \& Chang, Y. (2011A) Oil and Gold: Correlation or Causation? Nanyang Technological University, Singapore Working Paper Series No. 2011/22

13) Malliaris, A. G., \& Malliaris, M. (2009) Time series and neural networks comparison on gold, oil and the euro. In Neural Networks, International Joint Conference IEEE pp.19611967.

14) Melvin, M., \& Sultan, J. (1990) South African political unrest, oil prices, and the time varying risk premium in the gold futures market. Journal of Futures Markets, 10(2), pp.103-111.

15) Raza, N., Shahzad, S. J. H., Tiwari, A. K., \& Shahbaz, M. (2016) Asymmetric impact of gold, oil prices and their volatilities on stock prices of emerging markets. Resources Policy, 49, pp.290301.

16) Reboredo, J. C. (2013) Is gold a hedge or safe haven against oil price movements?. Resources Policy, 38(2), pp.130-137.

17) Simakova, J. (2011) Analysis of the Relationship between Oil and Gold Prices. Journal of Finance, 51(1), pp. 651-662.

18) Zhang, Y. J., \& Wei, Y. M. (2010) The crude oil market and the gold market: Evidence for cointegration, causality and price discovery. Resources Policy, 35(3), pp.168-177. 


\section{Appendices}

Appendix I : Testing of the Stationary of Variables : DF-GLS Unit root test

\begin{tabular}{|c|c|c|c|}
\hline Null Hypothesis & $\begin{array}{l}\text { Computed 't' } \\
\text { value }\end{array}$ & $\begin{array}{l}\text { Elliott-Rothenberg } \\
\text { DF-GLS Test critical } \\
\text { value at } 5 \%\end{array}$ & Result \\
\hline $\begin{array}{l}\text { Gold Prices has a } \\
\text { unit root }\end{array}$ & -1.599371 & -3.016000 & $\begin{array}{l}\text { Null Hypothesis } \\
\text { is accepted }\end{array}$ \\
\hline $\begin{array}{l}\text { Oil Prices has a } \\
\text { unit root }\end{array}$ & -2.305761 & -3.012000 & $\begin{array}{l}\text { Null Hypothesis } \\
\text { is accepted }\end{array}$ \\
\hline $\begin{array}{l}\text { Gold 1st } \\
\text { Difference } \\
\text { (Return) has a unit } \\
\text { root }\end{array}$ & -11.39548 & -3.013000 & $\begin{array}{l}\text { Null Hypothesis } \\
\text { is rejected }\end{array}$ \\
\hline $\begin{array}{l}\text { Oil 1st Difference } \\
\text { (Return) has a unit } \\
\text { root }\end{array}$ & -4.138716 & -3.017000 & $\begin{array}{l}\text { Null Hypothesis } \\
\text { is rejected }\end{array}$ \\
\hline
\end{tabular}

Appendix II : Results of Testing of Causality from Oil to Gold through Inflation Channel

Table II-A : Causality Results : Oil' Inflation

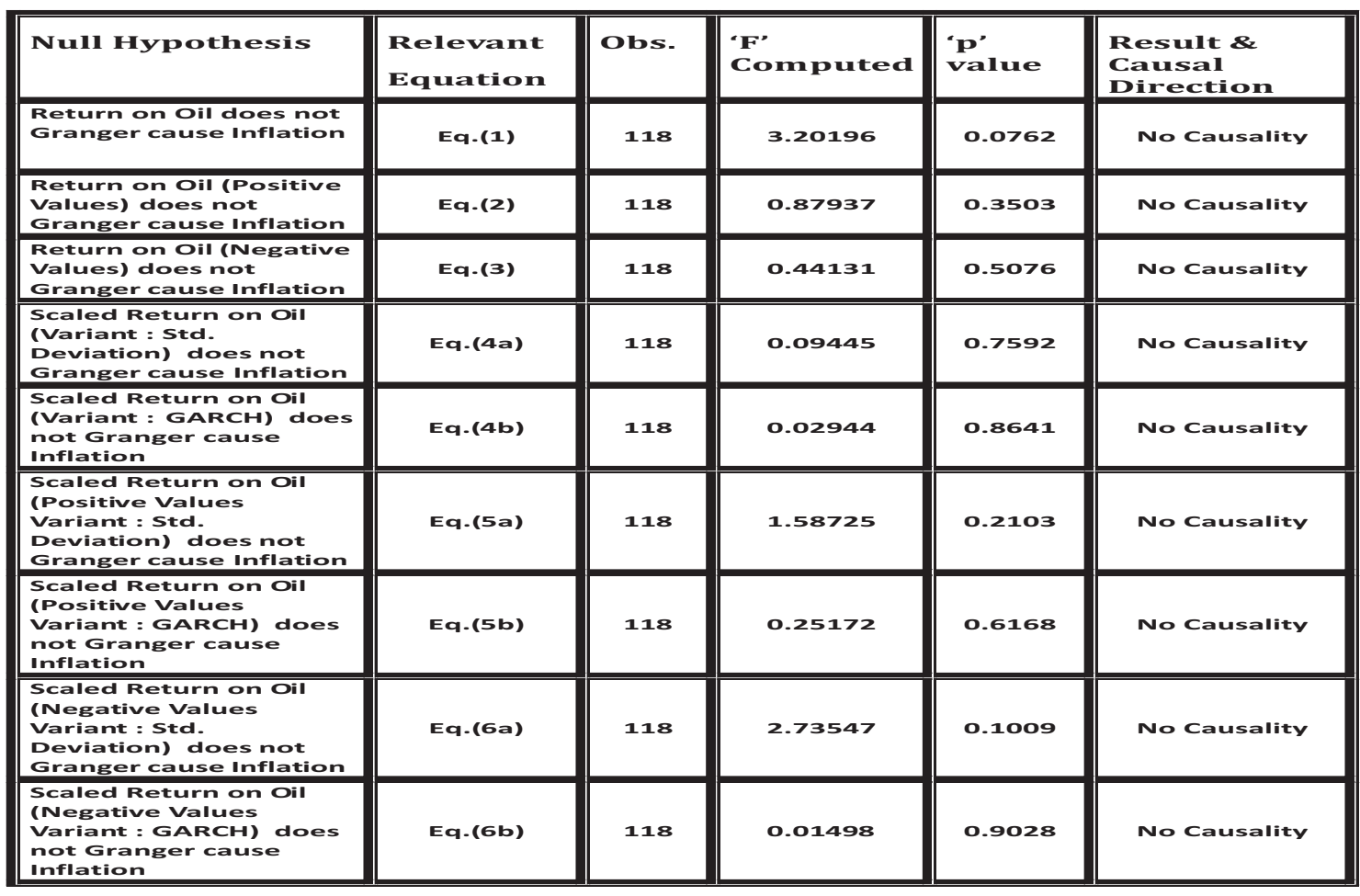


Table II-B : Causality Results : Inflation' $\rightarrow$ Gold

\begin{tabular}{|c|c|c|c|c|c|}
\hline Null Hypothesis & \begin{tabular}{|l|} 
Relevant \\
Equation \\
\end{tabular} & Obs. & \begin{tabular}{|l|} 
F' \\
Computed \\
\end{tabular} & 'p'value & $\begin{array}{c}\text { Result \& Causal } \\
\text { Direction }\end{array}$ \\
\hline $\begin{array}{l}\text { Inflation does } \\
\text { not Granger } \\
\text { cause Return } \\
\text { on Gold }\end{array}$ & Eq. $(6 c)$ & 117 & 2.95767 & 0.0030 & $\begin{array}{c}\text { Unilateral } \\
\text { Causality } \\
\text { Inflation } \rightarrow \text { Gold }\end{array}$ \\
\hline
\end{tabular}

Appendix III : Results of Testing of Causality from Oil to Gold (Direct route)

\begin{tabular}{|c|c|c|c|c|c|}
\hline Null Hypothesis & $\begin{array}{l}\text { Relevant } \\
\text { Equation }\end{array}$ & Obs. & $\begin{array}{l}' \text { F' } \\
\text { Computed }\end{array}$ & 'p' value & $\begin{array}{c}\text { Result \& } \\
\text { Causal } \\
\text { Direction }\end{array}$ \\
\hline $\begin{array}{l}\text { Return on Oil does } \\
\text { not Granger cause } \\
\text { Return on Gold }\end{array}$ & Eq.(7) & 117 & 1.35438 & 0.2623 & No Causality \\
\hline $\begin{array}{l}\text { Return on Oil } \\
\text { (Positive Values) } \\
\text { does not Granger } \\
\text { cause Return on } \\
\text { Gold }\end{array}$ & Eq.(8) & 117 & 1.10249 & 0.3356 & No Causality \\
\hline $\begin{array}{l}\text { Return on Oil } \\
\text { (Negative Values) } \\
\text { does not Granger } \\
\text { cause Return on } \\
\text { Gold }\end{array}$ & Eq.(9) & 117 & 0.81787 & 0.4440 & No Causality \\
\hline $\begin{array}{l}\text { Scaled Return on } \\
\text { Oil (Variant : Std. } \\
\text { Deviation) does not } \\
\text { Granger cause } \\
\text { Return on Gold }\end{array}$ & Eq.(10a) & 117 & 1.46571 & 0.1228 & No Causality \\
\hline $\begin{array}{l}\text { Scaled Return on } \\
\text { Oil (Variant : } \\
\text { GARCH) does not } \\
\text { Granger cause } \\
\text { Return on Gold }\end{array}$ & Eq.(10b) & 117 & 0.92961 & 0.4856 & No Causality \\
\hline $\begin{array}{l}\text { Scaled Return on } \\
\text { Oil (Positive Values } \\
\text { Variant : Std. } \\
\text { Deviation) does not } \\
\text { Granger cause } \\
\text { Return on Gold }\end{array}$ & Eq.(11a) & 117 & 0.01193 & 0.9160 & No Causality \\
\hline $\begin{array}{l}\text { Scaled Return on } \\
\text { Oil (Positive Values } \\
\text { Variant : GARCH) } \\
\text { does not Granger } \\
\text { cause Return on } \\
\text { gold }\end{array}$ & Eq. $(11 b)$ & 117 & 0.53350 & 0.5880 & No Causality \\
\hline $\begin{array}{l}\text { Scaled Return on } \\
\text { Oil (negative Values } \\
\text { Variant : Std. } \\
\text { Deviation) does not } \\
\text { Granger cause } \\
\text { Return on Gold }\end{array}$ & Eq.(12a) & 117 & 0.80587 & 0.4306 & No Causality \\
\hline $\begin{array}{l}\text { Scaled Return on } \\
\text { Oil (negative Values } \\
\text { Variant : GARCH) } \\
\text { does not Granger } \\
\text { cause Return on } \\
\text { gold }\end{array}$ & Eq.(12b) & 117 & 0.77403 & 0.5503 & No Causality \\
\hline
\end{tabular}


Appendix IV: Asymmetric Impact of Oil on Gold

Table IV (a) OLS Regression Results between Return on Gold (Dependent)

\& and Lags of Return on Oil , Lags of Return on Gold \& Positive and Negative Return on Oil (as Independent Variables)

\begin{tabular}{|c||r|r|r||}
\hline $\begin{array}{c}\text { Independent } \\
\text { Variables }\end{array}$ & Beta coeff & $\begin{array}{c}\text { Computed } \\
\text { ' } t \text { ' value }\end{array}$ & \multicolumn{1}{|c|}{$P^{\prime}$ value } \\
\hline \hline Gold Return Lag 1 & -0.645193 & -7.171793 & 0.0000 \\
\hline \hline Gold Return Lag 2 & -0.333449 & -3.583151 & 0.0005 \\
\hline \hline Positive Return on Oil & -0.260414 & -0.462384 & 0.6447 \\
\hline \hline Negative Return on Oil & 0.160181 & 0.352915 & $\underline{0.7248}$ \\
\hline \hline Oil Return Lag 1 & -0.330727 & -1.108182 & 0.2702 \\
\hline Oil Return Lag 2 & 0.405321 & 1.470477 & 0.1443 \\
\hline
\end{tabular}

Table IV (B) OLS Regression Results between Return on Gold (Dependent) \& and Scaled Lags of Return on Oil , Lags of Return on Gold \& Scaled Positive and Scaled Negative Return on Oil (as Independent Variables)

\begin{tabular}{|c||r|r|r||}
\hline $\begin{array}{c}\text { Independent } \\
\text { Variables }\end{array}$ & \multicolumn{1}{|c|}{ Beta coeff } & $\begin{array}{c}\text { Computed } \\
\text { 't'value }\end{array}$ & \multicolumn{1}{|c|}{$P^{\prime}$ value } \\
\hline \hline Gold Return Lag 1 & -0.645253 & -7.177915 & 0.0000 \\
\hline \hline Gold Return Lag 2 & -0.333420 & -3.582672 & 0.0005 \\
\hline \hline Scaled Positive Return on Oil & -0.024541 & -0.470052 & 0.6392 \\
\hline \hline Scaled Negative Return on Oil & 0.013790 & 0.324781 & 0.7460 \\
\hline \hline Scaled Oil Return Lag 1 & -0.031362 & -1.123577 & 0.2636 \\
\hline \hline Scaled Oil Return Lag 2 & 0.039600 & 1.519820 & 0.1314 \\
\hline
\end{tabular}


Table IV(c) : T-GARCH(1,1) Regression Results to detect asymmetry between Return on Gold (Dependent) \& Return on Oil (as Independent Variable)

\begin{tabular}{|c|c|c|c|}
\hline Mean Equation & Independent Variables & Beta coeff & 'P'value \\
\hline \multirow{3}{*}{ Variance Equation } & $\begin{array}{c}\text { C } \\
\text { OIL_PRICES }\end{array}$ & $\begin{array}{l}891.4631 \\
6.580603\end{array}$ & $\begin{array}{l}0.0000 \\
0.0000\end{array}$ \\
\hline & Independent Variables & Beta coeff & 'P'value \\
\hline & $\begin{array}{c}\mathrm{C} \\
\operatorname{RESID}(-1)^{\wedge} 2 \\
\operatorname{RESID}(\mathbf{- 1})^{\wedge} \mathbf{2}^{*}(\mathbf{R E S I D}(\mathbf{- 1})<\mathbf{0}) \\
\operatorname{GARCH}(-1)\end{array}$ & $\begin{array}{r}2643.802 \\
0.383516 \\
\mathbf{0 . 7 0 1 1 4 3} \\
0.137244\end{array}$ & $\begin{array}{r}0.0776 \\
0.0481 \\
\mathbf{0 . 0 9 1 9} \\
0.0229\end{array}$ \\
\hline
\end{tabular}

Appendix V : Optimal Lag Identification Criteria for Computation of Causality amongst variables

Table V-A : Lag Identification for Causality between Oil \& Inflation

\begin{tabular}{|c|c|c|c|c|c|}
\hline Lag & LR & FPE & AIC & SC & HQ \\
\hline & & & & & \\
\hline 0 & NA & 0.003869 & 0.121097 & $0.171951^{*}$ & $0.141700^{*}$ \\
\hline 1 & 9.690852 & $0.003797^{*}$ & $0.102071^{*}$ & 0.254632 & 0.163878 \\
\hline 2 & 2.273108 & 0.004008 & 0.156034 & 0.410302 & 0.259045 \\
\hline 3 & 5.311404 & 0.004098 & 0.178200 & 0.534176 & 0.322416 \\
\hline 4 & 3.472402 & 0.004269 & 0.218571 & 0.676255 & 0.403992 \\
\hline 5 & 2.283271 & 0.004502 & 0.270943 & 0.830334 & 0.497569 \\
\hline 6 & 5.460128 & 0.004584 & 0.287865 & 0.948963 & 0.555695 \\
\hline 7 & $16.02301^{*}$ & 0.004140 & 0.184754 & 0.947559 & 0.493789 \\
\hline 8 & 3.083192 & 0.004324 & 0.226238 & 1.090751 & 0.576478 \\
\hline 9 & 1.918739 & 0.004576 & 0.280588 & 1.246808 & 0.672032 \\
\hline 10 & 1.670791 & 0.004858 & 0.337381 & 1.405308 & 0.770030 \\
\hline 11 & 4.156293 & 0.005002 & 0.362992 & 1.532626 & 0.836845 \\
\hline 12 & 7.421001 & 0.004939 & 0.345978 & 1.617320 & 0.861036 \\
\hline 13 & 1.151815 & 0.005282 & 0.407943 & 1.780992 & 0.964205 \\
\hline 14 & 3.492001 & 0.005477 & 0.438306 & 1.913062 & 1.035773 \\
\hline 15 & 1.951327 & 0.005800 & 0.488498 & 2.064962 & 1.127170 \\
\hline
\end{tabular}


Table V-B: Lag Identification for Causality between Inflation \& Gold

\begin{tabular}{|c||c|c|c|c|c||}
\hline \hline Lag & LR & FPE & AIC & SC & HQ \\
\hline \hline 0 & NA & 0.066355 & 2.963010 & 3.013864 & 2.983612 \\
\hline \hline 1 & 37.54632 & 0.049413 & 2.668187 & 2.820748 & 2.729994 \\
\hline \hline 2 & 19.24674 & 0.043941 & 2.550699 & $2.804967^{*}$ & $2.653710^{*}$ \\
\hline \hline 3 & 10.09826 & 0.042774 & 2.523516 & 2.879492 & 2.667732 \\
\hline \hline 4 & 12.46462 & 0.040532 & 2.469233 & 2.926916 & 2.654654 \\
\hline \hline 5 & 1.871333 & 0.042932 & 2.526034 & 3.085424 & 2.752659 \\
\hline \hline 6 & 3.930799 & 0.044451 & 2.559761 & 3.220859 & 2.827592 \\
\hline \hline 7 & 15.69121 & 0.040303 & 2.460379 & 3.223184 & 2.769414 \\
\hline \hline 9 & 19.08332 & 0.035018 & 2.317953 & 3.182466 & 2.668193 \\
\hline \hline 10 & 6.015965 & 0.035318 & 2.324100 & 3.290320 & 2.715544 \\
\hline \hline 11 & $10.05479 *$ & $0.033891^{*}$ & $2.279881^{*}$ & 3.347808 & 2.712530 \\
\hline \hline 12 & 1.767647 & 0.035940 & 2.334982 & 3.504616 & 2.808835 \\
\hline 13 & 5.715156 & 0.036261 & 2.339561 & 3.610903 & 2.854619 \\
\hline \hline 14 & 2.202289 & 0.038252 & 2.387883 & 3.760932 & 2.944145 \\
\hline 15 & 5.206573 & 0.040788 & 2.439072 & 4.015535 & 3.077743 \\
\hline \hline
\end{tabular}

Table V-C : Lag Identification for Causality between Oil \& Gold

\begin{tabular}{|c|c|c|c|c|c|}
\hline Lag & LR & FPE & AIC & SC & HQ \\
\hline & & & & & \\
\hline 0 & NA & 0.000676 & -1.623334 & -1.572480 & -1.602731 \\
\hline 1 & 34.04660 & 0.000521 & -1.883506 & $-1.730945^{*}$ & -1.821699 \\
\hline 2 & 15.31605* & $0.000482^{*}$ & $-1.961290 *$ & -1.707022 & $-1.858278^{*}$ \\
\hline 3 & 7.075507 & 0.000484 & -1.957310 & -1.601335 & -1.813094 \\
\hline 4 & 4.356199 & 0.000500 & -1.926242 & -1.468559 & -1.740821 \\
\hline 5 & 6.601706 & 0.000503 & -1.920305 & -1.360915 & -1.693680 \\
\hline 6 & 3.176053 & 0.000525 & -1.878284 & -1.217186 & -1.610454 \\
\hline 7 & 2.092693 & 0.000555 & -1.824874 & -1.062069 & -1.515839 \\
\hline 8 & 2.595588 & 0.000583 & -1.777785 & -0.913273 & -1.427546 \\
\hline 9 & 0.550786 & 0.000627 & -1.707342 & -0.741122 & -1.315898 \\
\hline 10 & 5.954272 & 0.000632 & -1.702157 & -0.634230 & -1.269508 \\
\hline 11 & 3.027040 & 0.000660 & -1.662605 & -0.492970 & -1.188752 \\
\hline 12 & 1.336179 & 0.000704 & -1.602595 & -0.331254 & -1.087538 \\
\hline 13 & 1.389376 & 0.000750 & -1.543716 & -0.170667 & -0.987454 \\
\hline 14 & 1.375785 & 0.000800 & -1.485137 & -0.010381 & -0.887670 \\
\hline 15 & 1.915188 & 0.000848 & -1.434449 & 0.142014 & -0.795778 \\
\hline
\end{tabular}


Appendix VI Heteroskedasticity Test: ARCH

\begin{tabular}{llll}
\hline \hline F-statistic & 3787.113 & Prob. F $(1,308)$ & 0.0000 \\
Obs*R-squared & 286.6844 & Prob. Chi-Square(1) & 0.0000 \\
\hline \hline
\end{tabular}

\section{Appendix VII : CUSUM \& CUSUM SQ tests for Model Stability}
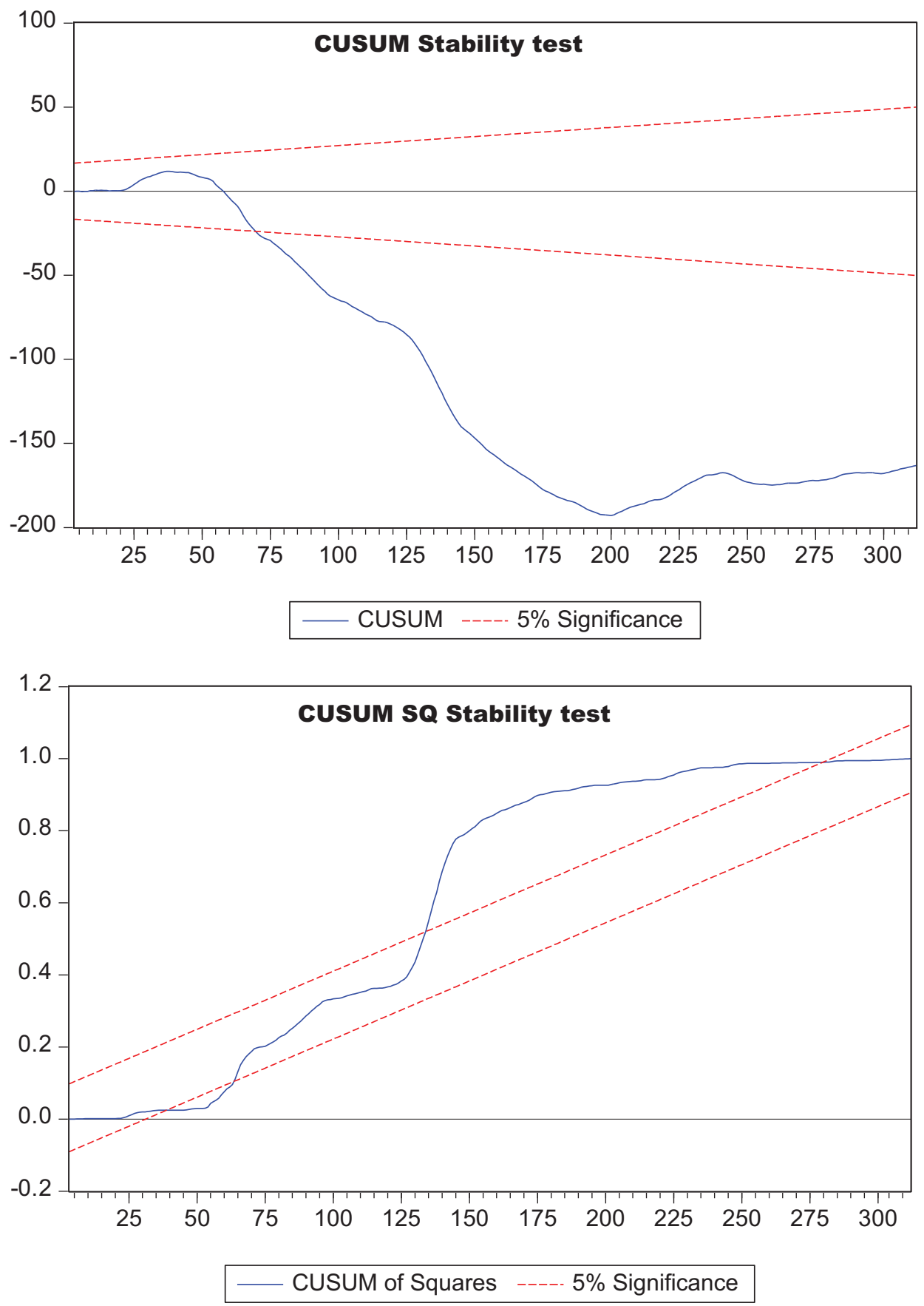